\title{
DNA Quantification to Assess Zymoseptoria tritici on a Susceptible Cultivar of Durum Wheat to Establish the Best Timing for Fungicide Application in an Italian Environment
}

\author{
S. Tonti ${ }^{1}$, G. Alvisi ${ }^{2}$, A. Pisi ${ }^{1}$, P. Nipoti ${ }^{1}$ and A. Prodi ${ }^{1 *}$ \\ ${ }^{1}$ Department of Agricultural and Food Sciences, Alma Mater Studiorum University of Bologna, \\ Bologna, Italy \\ ${ }^{2}$ Consorzio Agrario dell'Emilia, Research and Development, Test Facility, San Giorgio di Piano, \\ Bologna, Italy
}

(Received 14 February 2018; Accepted 11 January 2019;

Communicated by M. Taylor)

\begin{abstract}
Zymoseptoria tritici, a globally distributed pathogen, is responsible of Septoria tritici blotch (STB), one of the most damaging wheat diseases. In Italy the incidence of STB has increased during the past few years. The presence of $Z$. tritici on flag leaves of susceptible durum wheat plants, cultivar San Carlo, after a single artificial inoculation with two inoculum concentrations at different vegetative stages has been evaluated in the plain of Bologna (North of Italy), in a two year field study (2012-2013). The pathogen presence was also assessed in natural infection conditions after a fungicide application in the second year (2013). The results obtained, by visual examination (Incidence, Disease Severity) and DNA quantification by Real time PCR, demonstrated that BBCH 39 (flag leaf stage) is the most susceptible vegetative stage, independently of inoculum concentration and climatic conditions. A good correlation between Disease Severity and DNA quantity was observed in either sampling methods, entire flag leaves and flag leaf discs. Thereafter the most suitable period to obtain the best crop protection with only one fungicide treatment is the flag leaf stage.
\end{abstract}

Keywords: durum wheat, Zymoseptoria tritici, qPCR, fungicide

\section{Introduction}

Septoria tritici blotch (STB) is one of the most damaging disease of wheat and it is caused by Zymoseptoria tritici (Desm.) Quaedvlieg \& Crous (formerly known as Septoria tritici) (telomorph Mycosphaerella graminicola (Fuckel) J. Schröt.). Z. tritici is worldwide diffuse and recently has been placed among the top ten most important global pathogens (Dean et al. 2012). SBT is the most prelevant foliar disease of wheat in North and South America, Asia, North and Central Europe. In North Africa, Z. tritici is economically important only on durum wheat (Triticum durum), and intensive control measures are required to protect yields since the development of a robust, field-proven biocontrol system is still not available (O'Driscoll et al. 2014). In Italy the severity of STB infection, on

\footnotetext{
*Corresponding author; E-mail: antonio.prodi@unibo.it
} 
durum wheat varieties, has shown an exponential growth trend in the years from 2007 to 2010 with a further peak in 2013, followed by a slight decline in the years 2014 and 2015 (Pasquini et al. 2015) and a further increase in 2016. In the plain area of Bologna (Emilia Romagna region - North of Italy) the infection, in years with high inoculum pressure, caused yield losses up to $30 \%$.

There has been little work carried out on Z. tritici behavior in durum wheat, a cereal of great importance and tradition in Italy especially for production of good pasta quality. STB is mainly managed by fungicide applications and to a lesser extent by resistance breeding (Goudemand et al. 2013).

The aim of this study has been to define, in an Italian environment, a field protocol to determine the best timing for fungicide application against Zymoseptoria tritici on durum wheat using two different sampling methods (flag leaves and flag leaf discs) that employ DNA quantification.

The strain of $Z$. tritici inoculated on durum wheat was isolated from durum wheat, based on the observation that the majority of durum wheat cultivars are usually highly resistant to most $Z$. tritici isolated from bread wheat, whereas the majority of bread wheat cultivars are highly resistant to most $Z$. tritici isolated from durum wheat (Mirzadi Gohari et al. 2015).

\section{Material and Methods}

\section{Field trials}

Two-year field trials (2012-2013), in the plain of Bologna, Mezzolara (44 $36^{\circ} 17.90^{\prime \prime} \mathrm{N}-$ $\left.11^{\circ} 33^{\prime} 45.93^{\prime \prime}\right)$ and Dugliolo $\left(44^{\circ} 37^{\prime} 9.01^{\prime \prime} \mathrm{N}-11^{\circ} 34^{\prime} 20.71^{\prime \prime} \mathrm{E}\right)$ were carried out on c.v. San Carlo, a susceptible Italian durum wheat cultivar. Z. tritici strain-S1, isolated from durum wheat, was used for the artificial inoculation in both years. It was applied on the whole foliage, at different vegetative stages (BBCH 31, 39, 60), with two inoculum concentrations $\left(10^{5}\right.$ and $10^{6}$ conidia $\left./ \mathrm{mL}-100 \mathrm{ml} / \mathrm{m}^{2}\right)$ for the year 2012 and only one $\left(10^{5}\right.$ conidia/mL) for the year 2013. Plots with non-inoculated plants (NI) were assessed as control (Table 1).

Visual assessments, at BBCH 80 stage, were made on flag leaves and based on Incidence - I -, percentage of infected plants (assessment on 15 flag leaves/plot in 2012 and 20 in 2013); and on Disease Severity - DS - percentage of necrotic leaf area or lesions bearing pycnidia (Bronnimann 1968). The foliar sampling was performed in two different ways: entire flag leaves and flag leaf discs. In the year 2012 the sampling was done on 15 flag leaves/plot and in the year 2013 on flag leaf discs (two discs, $1 \mathrm{~cm}$ diameter, for each leaf) of 20 flag leaves/plot, in both artificial and natural trials. The flag leaf discs were obtained with a 2-hole punch and immediately transferred and cooled on ice.

In the second year (2013) the presence of Z. tritici was also evaluated in a natural infected trial, which was treated with Pyraclostrobin a.i., belonging to QoI fungicides family (commonly referred to as strobilurins), and distilled water (NT) at two vegetative stages (BBCH 31 and $\mathrm{BBCH} 39)$. The choice of Pyraclostrobin was done, in accordance 


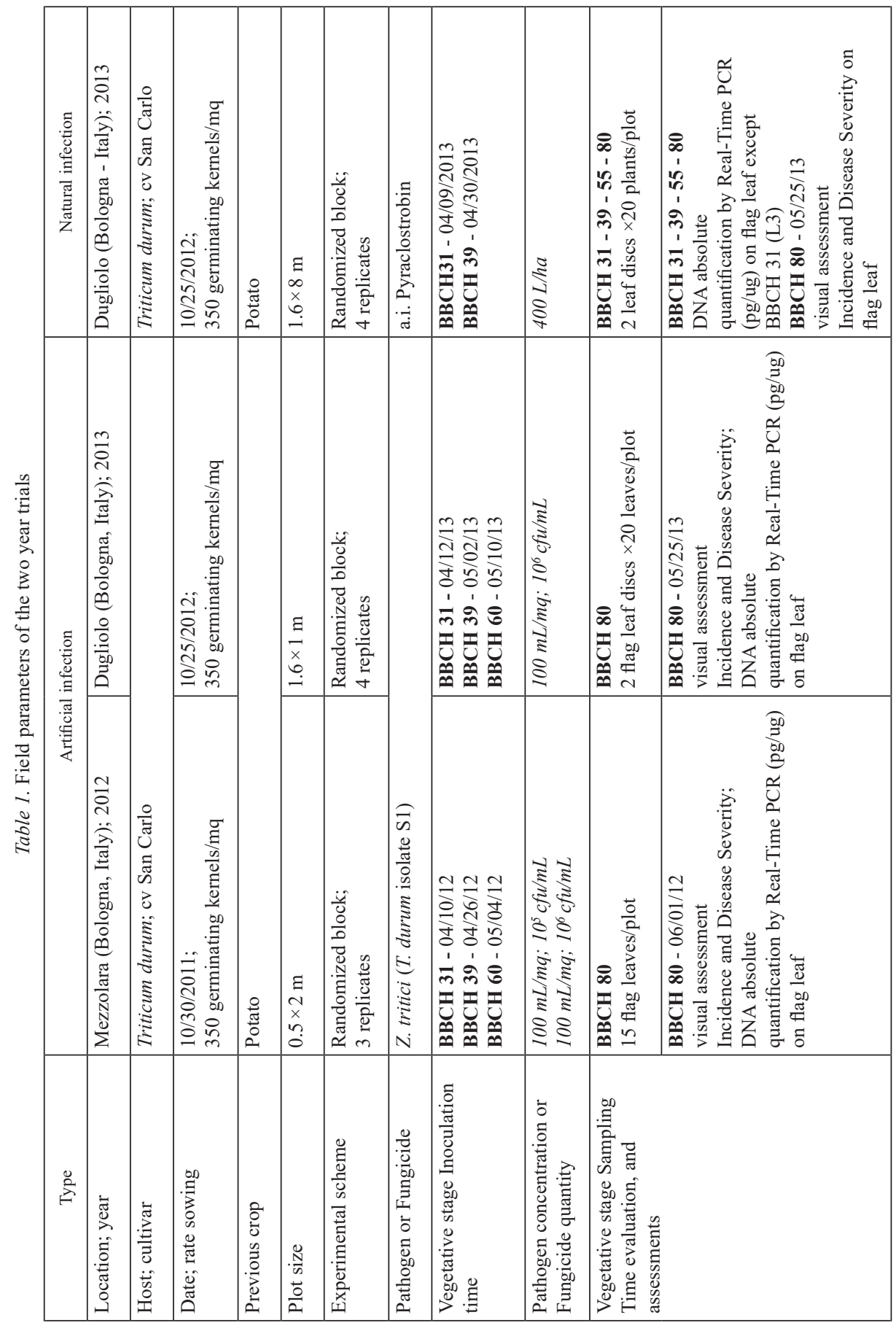

Cereal Research Communications 47, 2019 
to Alvisi et al. (2014), which reported that Pyraclostrobin efficacy was statistically equal to the other fungicides assayed in the same area of our experiment. In natural infected plots four samplings were carried out from BBCH31 to BBCH80 stages (Table 1).

The parameters of artificially and naturally infected field trials are shown in Table 1.

\section{RealTime PCR}

DNA absolute quantification was performed by Real time PCR, using the DNA extraction protocol based on CTAB method (Alkadri et al. 2013) and on the primer pair ST-rRNA $\mathrm{F} / \mathrm{R}$ (Guo et al. 2006). Each reaction was carried out in a volume of $20 \mu \mathrm{L}$ containing 12.5 $\mu \mathrm{L} \mathrm{GoTaq}^{\circledR}$ qPCR Master Mix (Promega), $0.25 \mu \mathrm{L}$ CXR (100X) reference dye, $0.40 \mu \mathrm{L}$ from each primers $(10 \mu \mathrm{M}), 6.45 \mu \mathrm{L}$ Nuclease-Free Water and $5 \mu \mathrm{L}$ of cDNA. PCRs amplification was performed under the following conditions: $95^{\circ} \mathrm{C}$ for $15 \mathrm{~min}$, followed by 40 cycles at $95^{\circ} \mathrm{C}$ for $15 \mathrm{~s}$ and $65^{\circ} \mathrm{C}$ for $15 \mathrm{~s}$. Melting curve analysis was performed at the end of each reaction to confirm the amplification of gene-specific products.

\section{Statistical analyses}

Error standard (SE) is calculated for the mean values of Incidence and Disease Severity. Correlation coefficients $\mathrm{R}^{2}$ of independent replicates at $95 \%$ level of significance are calculated for the parameters of the field trials and the data of DNA quantification.

\section{Results}

The field trial in the year 2012 showed the highest I and DS values at $\mathrm{BBCH} 39$, significantly different from those at $\mathrm{BBCH} 31$ and non inoculated (NI), independently by the inoculum concentrations (Figs 1A and 1B). In the year 2013 DS values ranged from 35 to $55 \%$ and in 2012 were all below 25\% (Fig. 2). The year 2012 was characterized by low infection pressure of the pathogen probably due to low rainfall in March and April, while the year 2013 by a high infection pressure ascribed to heavy rains (Fig. 3). These rain splashes allowed a better $Z$. tritici pycnidiospore dispersions throughout the canopy (Shaw and Royal 1993; Shaw 1987) with consequently higher DS values.

DNA quantifications showed a trend comparable to visual scores in both years (Figs 1 and 2).

Table 2. Correlation coefficients $\mathrm{R}^{2}$ between visual assessment (I and DS) and Z. tritici DNA quantification $(\mathrm{pg} / \mu \mathrm{g})$ at level of significance $95 \%(*)$ and not significant (n.s.)

\begin{tabular}{|l|c|c|c|}
\hline & $\begin{array}{c}\text { Artificial Infection } \\
2012\end{array}$ & $\begin{array}{c}\text { Artificial Infection } \\
2013\end{array}$ & $\begin{array}{c}\text { Natural Infection } \\
2013\end{array}$ \\
\hline & DNA & DNA & DNA \\
\hline I & $0.6422^{*}$ & 1 & 0.5885 n.s. \\
\hline DS & $0.6922^{*}$ & $0.8742 *$ & $0.9949 *$ \\
\hline
\end{tabular}


In Table 2 the correlation coefficients $\mathrm{R}^{2}$ between the parameters of visual assessment (I and DS) and DNA quantification are reported. A good correlation between DS and DNA was obtained even if the sampling methods of the two year trials were different.
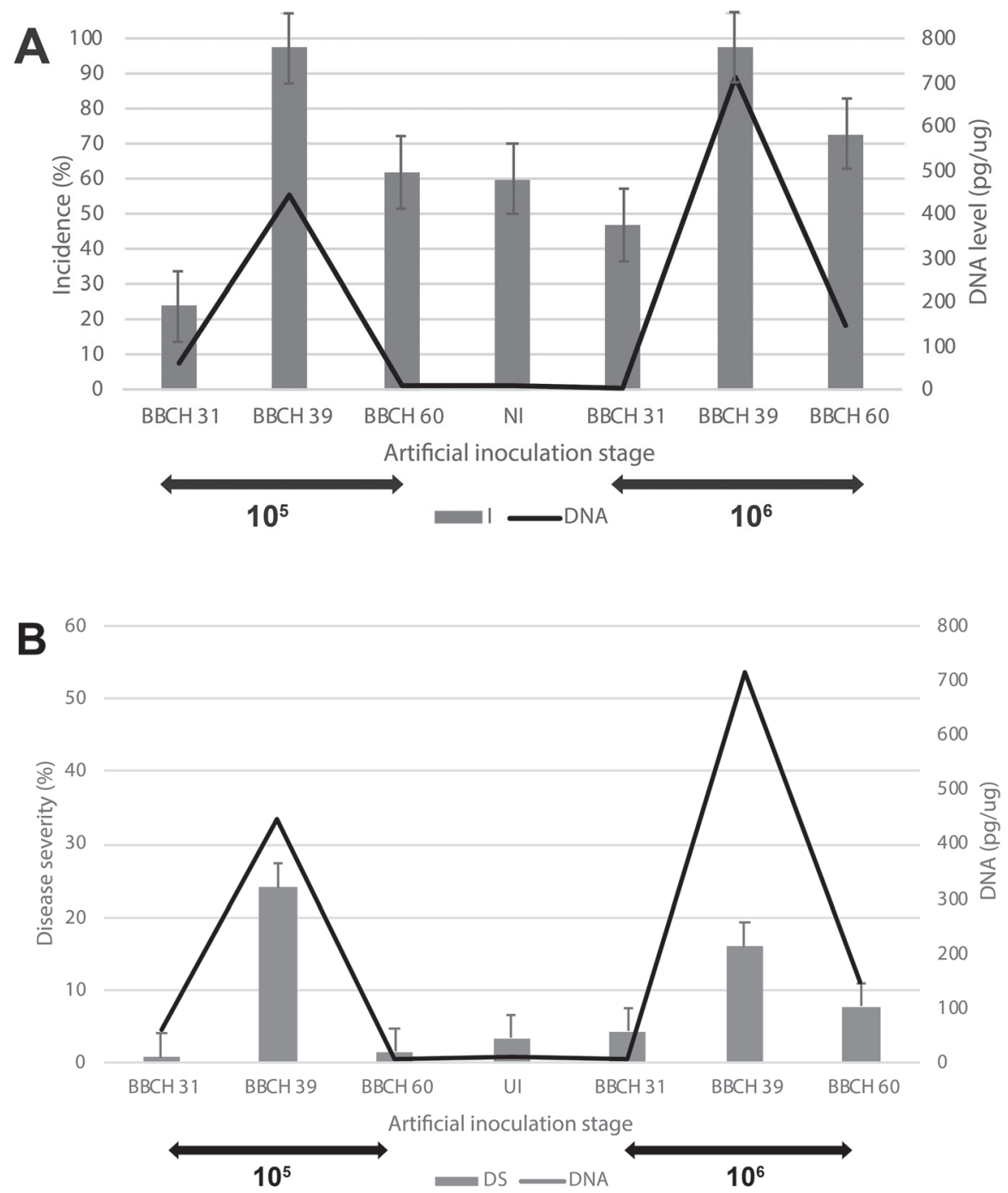

Figure 1. Year 2012 - Incidence (I \%) (A) and Disease Severity (DS \%) (B), in columns, compared to DNA quantification $(\mathrm{pg} / \mu \mathrm{g})($ line $)$ at two inoculum concentration $\left(10^{5}\right.$ and $10^{6}$ conidia $\left./ \mathrm{mL}\right)$ and three different inoculation stages $(\mathrm{BBCH}), \mathrm{NI}=$ non-inoculated. Values are means and error bars represent $\mathrm{SE}$ 


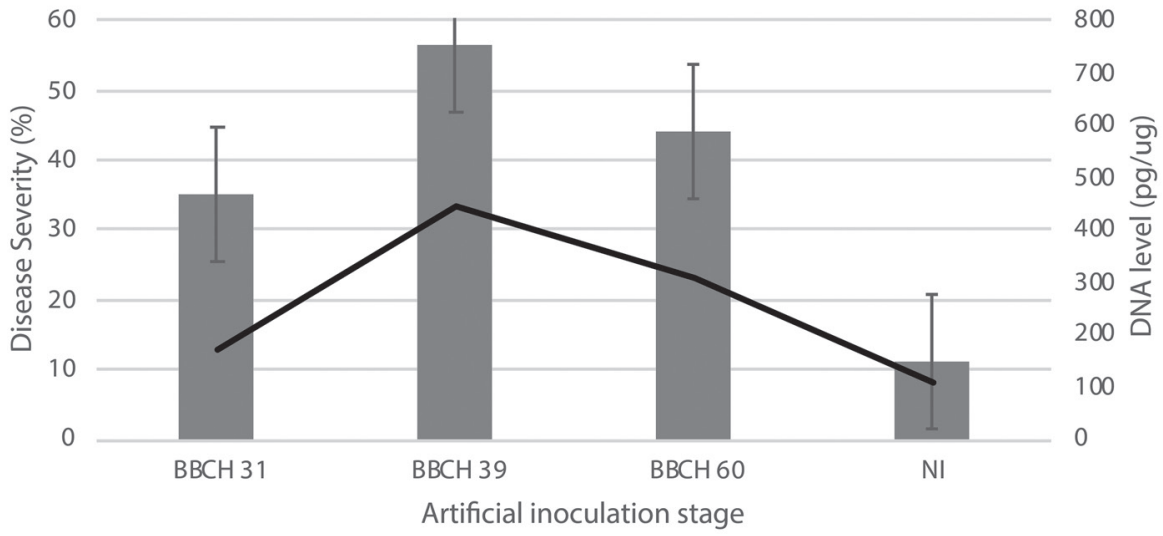

DS - DNA

Figure 2. Year 2013 - Disease Severity (DS \%) (columns) compared to DNA quantification (pg/ $\mu$ g) (line) at different inoculation stages $(\mathrm{BBCH}), \mathrm{NI}=$ non-inoculated. Values are means and error bars represent $\mathrm{SE}$

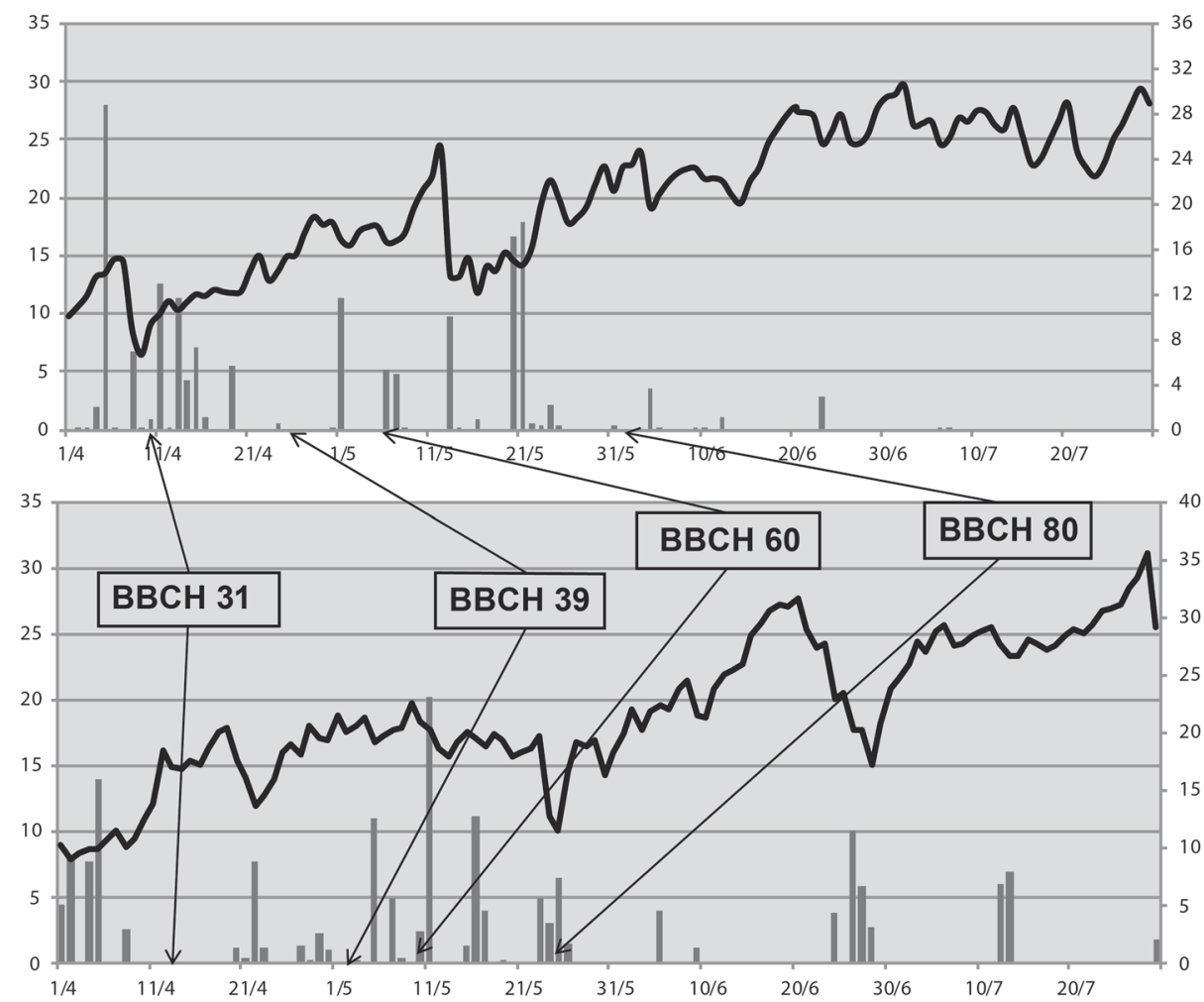

Figure 3. Climatic data recorded during the two experimental years (2012 and 2013): average temperatures (graph), rainfalls (columns) and wheat growth stages (boxes) 


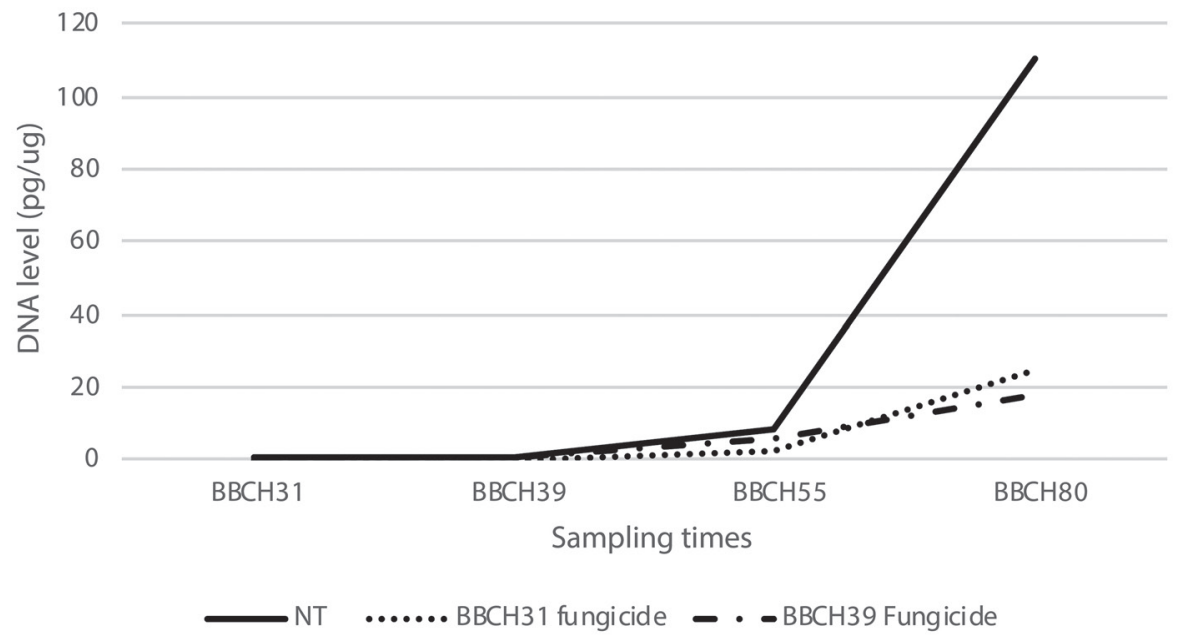

Figure 4. Year 2013 - Z. tritici DNA quantification (pg/ $\mu \mathrm{g})$ at different sampling times in non-treated (NT) and treated with Pyraclostrobin (BBCH 31 and $\mathrm{BBCH} 39)$

In the natural infection trial, Z. tritici DNA quantification at four different sampling times (BBCH 31 - 39 - 55 - 80) showed a low fungal presence at $\mathrm{BBCH} 55$ stage followed by a rapid and high fungal increase. At $\mathrm{BBCH} 80$ the treated plots showed a high reduction of Z. tritici presence towards NT (Fig. 4).

The results by visual assessment are shown in Figure 5. Pyraclostrobin application at BBCH 39 stage significantly reduced I $(72 \%)$ compared to BBCH31 (I $=92 \%)$. Moreover Z. tritici DNA quantification is highly correlated to DS $\left(\mathrm{R}^{2}=0.9949^{*}\right)$ (Table 2).

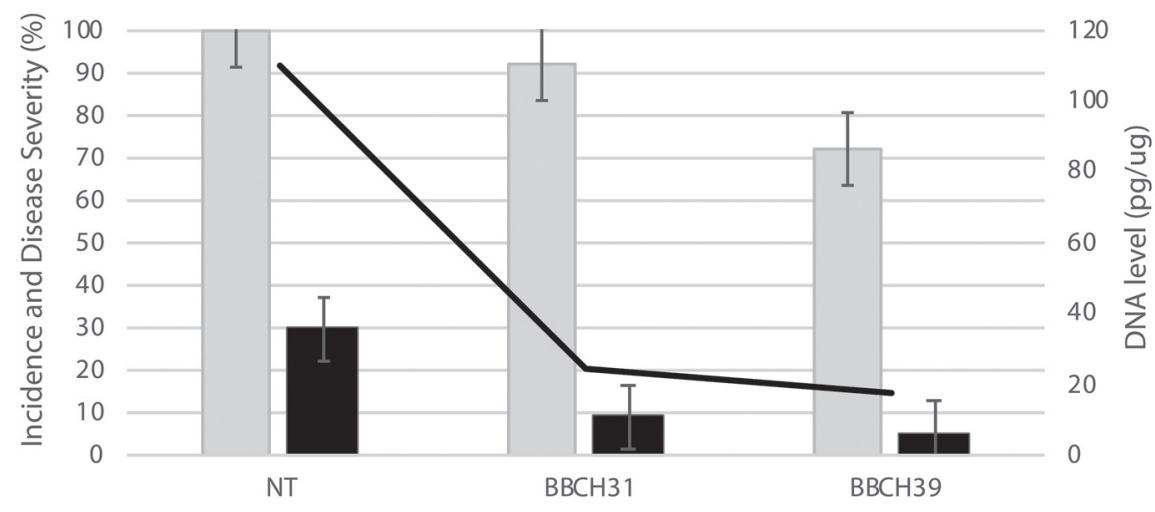

Fungicide application timing

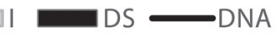

Figure 5. Year 2013 - Results of visual assessment (I and DS) (\%) compared to DNA quantification (pg/ $\mu \mathrm{g})$ at different Pyraclostrobin application times $(\mathrm{BBCH})$ and non-treated $(\mathrm{NT})$. Values are means and error bars represent $\mathrm{SE}$ 


\section{Discussion}

The data of both years showed that in the tested environment a single pycnidiospore inoculation on durum wheat is sufficient to induce symptoms on flag leaves also at the lowest assayed inoculum concentration.

A good correlation between DS and DNA was obtained even if the sampling methods of the two-year trials were different. This demonstrates that the sampling method (leaf discs) applied in year 2013 was effective but much simpler than that used in year 2012, which utilizes 15 whole leaf blades and that one reported by Guo et al. (2006) that used 10-12 leaves. Furthermore, DNA extraction with the leaf discs method was faster because the grinding was easier. This result shows that this method is more efficient and should be applied in further experiments.

An accurate and early assessment of population densities is a basis for precise diagnosis of the disease and essential to fix the timing in fungicide applications (Fraaije et al. 1999). A fungicide treatment based only on visual diagnosis leads to partial success in terms of disease control since the fungal latent period is around four weeks. Therefore, early prediction by realTime PCR is of great importance for Z tritici management.

The results of the natural infection trial pointed out that a single fungicide application against $Z$. tritici is sufficient and effective to obtain good results in the Italian environment; differently from France, Germany and UK, where usually a 3 spray fungicide regime is practiced with a fungicide cost of about 100 Euros per hectar (Torriani et al. 2015). This is an important result, taking into consideration that the timing for fungicide application, as stated by Fones and Gurr (2015), is somewhat problematic in the EU contest, since it is difficult to match it with disease progression. The data obtained underline that the flag leaf stage could be the most suitable period to obtain the best crop protection. It is important to keep flag leaves in good health since they greatly contribute (about $45-50 \%$ ) to the yield; any physiological or pathological degeneration could significantly decrease the photosynthetic surface.

An integrated strategy would couple the effect of enhancing sustainability of food systems (e.g. quality and safety issues) related to wheat, and to new innovative solutions to limit the use of pesticides to control STB. The development of active substances with both protectant and curative activity gives the growers the opportunity to capitalize on fungicide regimes with high and reliable levels of control (O'Driscoll et al. 2014). However, these strategies have some disadvantages such as increasing pathogen resistance, as occurred with QoIs, or increasing the levels of fungicide insensitivity, as currently being witnessed with DMIs (O'Driscoll et al. 2014). The resistance to QoIs, that acts against mitochondrial protein cytochrome $b$, is common in the main wheat cultivated areas, therefore a G143A mutation in the cytochrome $b$ protein sequence causes loss of efficacy (Fraaije et al. 2005). In Europe Z. tritici QoIs field resistance was first reported in UK in 2001 (Fraaije et al. 2005), but up to now there are no reports about it in Italy. Interesting Torriani and collaborators (2009) demonstrated that the resistance allele G143A was acquired independently at least four times in Europe. 
In conclusion, this work confirms that only one treatment, mostly at $\mathrm{BBCH} 39$ stage, is sufficient to reach a good control of STB in the area investigated. Until few years ago, Northern Italian farmers performed the fungicide treatment against STB, at BBCH31 stage in association with an herbicide treatment, because it is most cost-effective. This attitude allows an increase in pathogen resistance since $Z$. tritici is able to complete several generations of ascospores after disease establishment (Kema et al. 1996). The presence of the sexual stage supports the high rate of ascospore dissemination by wind, a compounding factor in the spread of fungicide-resistant isolates (Fraaije et al. 2005). From the ecological point of view, a single early treatment does not eradicate the pathogen, but could select resistant strains; conversely a single late treatment, which reduces the chemical pressure on the exponential phase of the infection, can decrease the selection of resistant or tolerant strains, shortening the period favorable to the spread of survivors.

\section{References}

Alkadri, D., Nipoti, P., Döll, K., Karlovsky, P., Prodi, A., Pisi, A. 2013. Study of fungal colonization of wheat kernels in Syria with a focus on Fusarium species. Int. J. Mol. Sci. 14:5938-5951.

Alvisi, G., Cristiani, C., Ponti, D., Betti, C., Ferrari, A. 2014. Grano duro: lotta alla septoriosi, quale strategia di difesa usare. Supplemento Informatore Agrario, "Cereali - difesa e nutrizione", 9:20-23.

Bronnimann, A. 1968. Investigations of Septoria nodorum Berk. of wheat. Mitt. Schveiz. Landwirt. 16:65-67.

Dean, R., Van Kan, J.A., Pretorius, Z.A., Hammond-Kosack, K.E., Di Pietro, A., Spanu, P.D., Rudd, J.J., Dickman, M., Kahmann, R., Ellis, J. 2012. The Top 10 fungal pathogens in molecular plant pathology. Mol. Plant Path. 13:414-430.

Fones, H., Gurr, S. 2015. The impact of Septoria tritici Blotch disease on wheat: An EU perspective. Fungal Gen. and Biol. 79:3-7.

Fraaije, B., Lovell, D.J., Rohel, E.A., Hollomon D.W. 1999. Rapid detection and diagnosis of Septoria tritici epidemics in wheat using a polymerase chain reaction/Pico green assay. J. Appl. Microbiol. 86:701-708.

Fraaije, B.A., Cools, H.J., Fountaine, J., Lovell, D.J., Motteram, J., West, J.S., Lucas, J.A. 2005. The role of ascospores in further spread of QoI-resistant cytochrome b alleles (G143A) in field populations of Mycosphaerella graminicola. Phytopathol. 95:933-941.

Goudemand, E., Laurent, V., Duchalais, L., Tabib Ghaffary, S.M., Kema, G.H.J., Lonnet, P., Margalé, E., Robert, O. 2013. Association mapping and meta-analysis: two complementary approaches for the detection of reliable Septoria tritici blotch quantitative resistance in bread wheat (Triticum aestivum L.). Mol. Breed. 32:563-584.

Guo, J.R., Schneider, F., Verreet, J.A. 2006. Presymptomatic and quantitative detection of Mycosphaerella graminicola development in wheat using Real Time PCR. FEMS Microbiol. Lett. 262:223-229.

Kema, G.H.J., Verstappen, E.C., Todorova, M., Waalwijk, C. 1996. Successful crosses and molecular tetrad and progeny analyses demonstrate heterothallism in Mycosphaerella graminicola. Curr. Genet. 30:251-258.

Mirzadi Gohari, A., Ware, S.B., Wittenberg, A.H.J., Mehrabi, R., Ben M'Barek, S., Verstappen, E.C.P., van der Lee, T., Robert, O., Schouten, H., de Wit, P., Kema, G. 2015. Effector discovery in the fungal wheat pathogen Zymoseptoria tritici. Mol. Plant Path. 16:931-945.

O’Driscoll, A.O., Kildea, S., Doohan, F., Spink, J., Mullins, E. 2014. The wheat-Septoria conflict: a new front opening up?. Trends Plant Sci. 19:602-610.

Pasquini, M., Iori, A., Nocente, F., Sereni, L., Cacciatori, P., Cristofori, C., Caprara, F., Codianni, P., Licciardello, S., Martelli, M., Notario, T., Petrini, A., Podda, E., Randazzo, B., Viola, P. 2015. Sensibilità dei frumenti alle principali malattie fungine. L'informatore agrario 39:42-46.

Shaw, M.W. 1987. Assessment of upward movement of rain splash using a florescent tracer method and its application to the epidemiology of cereal pathogens. Plant Pathol. 36:201-213. 
Shaw, M.W., Royle, D.J. 1993. Factors determining the severity of epidemics of Mycosphaerella graminicola (Septoria tritici) on winter wheat in the UK. Plant Pathol. 42:882-899.

Torriani, S.F.F., Brunner, P.C., McDonald, B.A., Sierotzki, H. 2009. QoI resistance emerged independently at east 4 times in European populations of Mycosphaerella graminicola. Pest Manag. Scie. 65:155-162.

Torriani, S., Melichar, J., Mills, C., Pain, N., Sierotzki, H. 2015. Zymoseptoria tritici: A major threat to wheat production, integrated approaches to control. Fungal Gen. and Biol. 79:8-12. 